\title{
Tunnelling techniques hold key to prospects for giant accelerator
}

[WASHINGTON] Advances in tunnelling and materials technology could revitalize plans dreamt up in the 1980s to build a vast accelerator ring up to $1,000 \mathrm{~km}$ in circumference in the United States, according to physicists at Fermilab - the Fermi National Accelerator Laboratory - outside Chicago.

A small team working on future accelerator concepts believes that new techniques for automated tunnelling, together with the future availability of superconducting cable to power simple iron electromagnets, could make possible the construction of a giant ring able to achieve more than ten times the energy of Europe's planned Large Hadron Collider (LHC).

But, since the Fermilab team began to study the concept seriously in November 1995, it has encountered serious obstacles. Robotic boring devices being developed by civil engineers to plant pipes beneath rivers and streets are unlikely to enhance the project's viability as much as had been hoped.

Another hadron collider is one of the options being explored by physicists as they look beyond the capability of the LHC, which is due to be completed in 2005 at CERN, the European laboratory for particle physics in Geneva, Switzerland.

Rival teams are also developing less exotic concepts for linear electron colliders, and for machines to examine collisions of muons, unstable particles of intermediate mass.

Anyone wanting to design an even larger hadron collider has two options: to pursue a far more powerful magnetic field (as have the designers of the LHC, which is an upgrade to CERN's existing ring), or to look to a much larger ring. Advocates of a larger ring have named it the Pipetron, and are seeking to develop their concept into a project that could one day gain public support.

The Pipetron could, its advocates believe, use a C-section magnet to focus and gently steer the hadron beam, rather than the more complex combination of bipolar and quadrupole magnets used in more compact accelerator rings. The first prototype of a short section of such a magnet is now being built at Fermilab, which will spend a modest $\$ 200,000$ on the concept this year.

"We have the feeling that this is a low-cost approach, but we have to prove that," says Ernie Malamud, who is working on the Pipetron concept at Fermilab. The concept could be viable, he says, because technologies have changed so much since it was previously contemplated, in the early 1980 s.

Malamud cites high-temperature superconductors, as well as digital electronics for control and monitoring, as examples. But it was the potential of 'microtunnelling' - the use of remotely controlled machines to dig small-bore tunnels cheaply - that Pipetron advocates hoped would lead to significant cost breakthroughs.

"The community is looking for ways to lower the cost of expanding the energy frontier," says Malamud. An added advantage of the Pipetron concept, he says, is that the drilling technology developed to build it might help public utilities to put cables and pipes underground, as the public wishes.

Industrial corporations are showing interest in the concept, which they view as an opportunity to develop at least three important technologies. Paul Grant of the Electric Power Research Institute, an electric utilities

\section{Prime minister heads Indian science panel}

[NEW DELHI] India's prime minister, H. D. Dewe Gowda, is to head a committee on science and technology that has been set up to help accelerate research and the application of technology to national development. The other members of the panel will be cabinet ministers in charge of science, finance, agriculture, defence, industry, rural development and education.

The government has also revived the scientific advisory committee to the cabinet which became defunct in 1989 after the death of the then prime minister, Rajiv Gandhi. It will be made up of leading scientists from government and industry, headed by an eminent scientist.

While the committee will formulate policies and specific programmes, the cabinet panel will provide the political backing needed to translate its proposals into action. A committee made up of the secretaries of the various science-funding departments, headed by the cabinet secretary, will be responsible for implementing the programmes.

Ragunath Mashelkar, secretary to the Department of Scientific and Industrial Research, says that the setting-up of these committees is a signal that funding prospects for Indian science may improve in the next financial year. India's total spending on scientific research fell from 1.1 per cent of its gross domestic product in 1990 to 0.83 per cent in 1996 .

K.S. Jayaraman

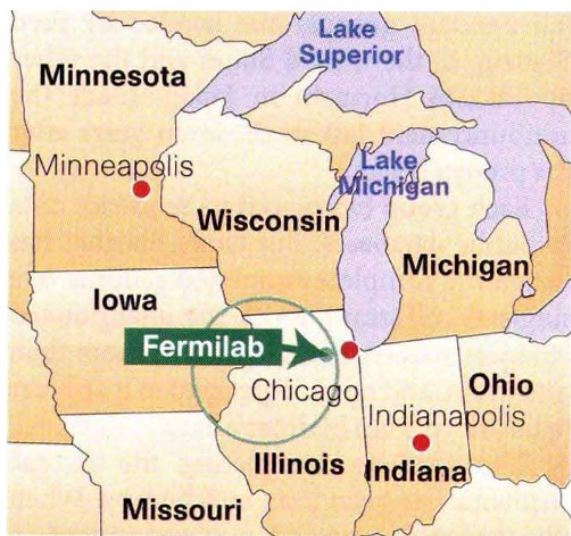

Ring road: Pipetron would form a tunnel of up to $1,000 \mathrm{~km}$ in circumference beneath the mid-west.

research consortium based in Palo Alto, California, says that the project could help to pioneer automated tunnelling, superconducting cable for power transmission, and the use of robots for construction and maintenance in small tunnels.

Physicists at Fermilab foresee a machine of up to $1,000 \mathrm{~km}$ in circumference, dug in a consistent slab of dolomite rock and extending from the laboratory site. Fermilab's director, John Peoples, stresses that the Pipetron is only one of the approaches the laboratory is considering for its own future after the LHC supplants Fermilab's Tevatron as the world's most powerful hadron collider. The main problem, he says, is cost.

Peoples says that costs per $\mathrm{TeV}$ would have to come down by an order of magnitude from those of the ill-fated Superconducting Super Collider, abandoned in Texas in 1994, if a machine is to have a chance of being built. He believes that automated boring of smallbore tunnels followed by automated operation "with no human access" is needed to achieve such a cost breakthrough.

But, after consulting tunnelling engineers, the Pipetron team is becoming less sanguine about automated tunnelling or drilling. "We're told it's cheaper to be bigger," says Malamud. "We got talked out of the original idea of a non-accessible tunnel."

According to Jim Friant, a Seattle-based tunnelling consultant who has advised the Pipetron team, today's cheapest tunnels are $14 \mathrm{ft}$ in diameter. This could be brought down to $8 \mathrm{ft}$, he says. With anything smaller, men cannot get to the front to replace cutters while the machine is in place.

Small, remotely controlled tunnel cutters are liable to get stuck, and are hard to steer. The concept of a robot that could dig the Pipetron cheaply appears, for now, to be merely a pipe dream.

ColinMacilwain 